\title{
Supercapatteries as High-Performance Electrochemical Energy Storage Devices
}

\author{
Linpo $\mathrm{Yu}^{1} \cdot$ George Zheng Chen ${ }^{1,2}(\mathbb{0}$
}

Received: 1 April 2019 / Revised: 19 November 2019 / Accepted: 20 January 2020 / Published online: 26 February 2020

(C) The Author(s) 2020

\begin{abstract}
The development of novel electrochemical energy storage (EES) technologies to enhance the performance of EES devices in terms of energy capacity, power capability and cycling life is urgently needed. To address this need, supercapatteries are being developed as innovative hybrid EES devices that can combine the merits of rechargeable batteries with the merits of supercapacitors into one device. Based on these developments, this review will present various aspects of supercapatteries ranging from charge storage mechanisms to material selection including electrode and electrolyte materials. In addition, strategies to pair different types of electrode materials will be discussed and proposed, including the bipolar stacking of multiple supercapattery cells internally connected in series to enhance the energy density of stacks by reducing the number of bipolar plates. Furthermore, challenges for this stack design will also be discussed together with recent progress on bipolar plates.
\end{abstract}

Keywords Supercapattery $\cdot$ Supercapacitor $\cdot$ Capacitive and non-capacitive Faradic processes $\cdot$ Nanocomposites $\cdot$ Nonaqueous electrolyte $\cdot$ Device engineering

\begin{tabular}{|c|c|c|c|}
\hline List of Symbols & & GCDs & Galvanic charge and discharge plots \\
\hline C & Capacitance & EDLCs & Electrical double-layer capacitors \\
\hline$q$ & Charge & ESR & Equivalent series resistance \\
\hline$U$ & Voltage & Act-Cs & Activated carbons \\
\hline$i$ & Current & TMOs & Transition metal oxides \\
\hline$W$ & Energy & ECPs & Electronically conducting polymers \\
\hline$P$ & Power & PoAP & Poly $(o$-aminophenol $)$ \\
\hline$E_{\mathrm{g}}$ & Energy gap & CNTs & Carbon nanotubes \\
\hline E & Potential & PANI & Polyaniline \\
\hline$F$ & Faraday constant & Positrode & Positive electrode \\
\hline$R$ & Gas constant & Negatrode & Negative electrode \\
\hline$T$ & Temperature & PPy & Polypyrrole \\
\hline & & IL & Ionic liquid \\
\hline $\begin{array}{l}\text { Abbreviations } \\
\text { EES }\end{array}$ & Electrochemical energy storage & BMPyrrFAP & 1-Butyl-1-methylpyrrolidinium \\
\hline $\mathrm{CVs}$ & Cyclic voltammograms & $\gamma-\mathrm{GBL}$ & $\begin{array}{l}\text { tri(pentafluoroethyl)trifluorophosphate } \\
\text { gamma-Butyrolactone }\end{array}$ \\
\hline$\triangle$ George Zheng & Chen & & bis(trifluoromethylsulfonyl)imide \\
\hline $\begin{array}{l}\text { george.chen@ } \\
\text { http://www.no }\end{array}$ & $\begin{array}{l}\text { nottingham.ac.uk } \\
\text { ttingham.ac.uk/ enzgzc }\end{array}$ & AQ-PFS ${ }^{-}$ & $\begin{array}{l}\text { Perfluorosulfonate anion bearing } \\
\text { anthraquinone }\end{array}$ \\
\hline $\begin{array}{l}\text { Department of } \\
\text { Faculty of Sci }\end{array}$ & $\begin{array}{l}\text { Chemical and Environmental Engineering, } \\
\text { ence and Engineering, and Key Laboratory }\end{array}$ & TEMPO -MI ${ }^{+}$ & $\begin{array}{l}\text { Methyl imidazolium cation bearing } \\
2.2 .6 .6 \text {-tetramethylniperidinyl-1-oxyl }\end{array}$ \\
\hline of More Elect & ic Aircraft Technology of Zhejiang Province, & NFCS & Non-Faradaic capacitive storage \\
\hline $\begin{array}{l}\text { University of I } \\
\text { Zhejiang, Chi }\end{array}$ & $\begin{array}{l}\text { Nottungnam Ningbo Cnina, Ningbo } 315100 \text {, } \\
\text { aa }\end{array}$ & CFS & Capacitive Faradaic storage \\
\hline Department of & Chemical and Environmental Engineering & NCFS & Non-capacitive Faradaic storage \\
\hline
\end{tabular}




\section{Introduction}

Energy derived from intermittent renewable sources such as solar, wind and tide must be stored and supplied in efficient and affordable means to become viable alternatives to traditional non-renewable options. This need has led to the strong desire for energy storage technologies that can be applied to different sustainable energy applications. To address this, researchers have reported that electrochemical energy storage (EES) technologies can be suitable for energy harvesting at various scales and are more attractive than current popular technologies using pumped-storage hydroelectricity, for example [1]. Here, desirable EES devices should possess sufficiently large energy and power capabilities, long cycling lifespans and be commercially affordable. Although rechargeable batteries possess sufficiently large energy capacities, and supercapacitors possess high-power capabilities and long cycle lifespans with great progress being made in both in the past two decades, each technology alone cannot satisfy all the requirements for successful commercialization. To address this, various hybrid EES devices have been proposed and preliminarily demonstrated in which such hybrid devices can combine the merits of supercapacitors with those of rechargeable batteries into one device. However, a unified generic term was lacking for these devices and researchers have generally referred to them using different nomenclatures such as 'redox capacitors' [2, 3], 'Li-ion capacitors' [4-8], 'Naion capacitors' [8-10], 'hybrid electrochemical capacitors' [11-14], battery-supercapacitor hybrids [15] or 'pseudocapacitors' [16-18] corresponding to electrode material and device design and engineering. As a result, a generic term 'supercapattery' (= supercapacitor + battery) was proposed to represent these EES hybrid devices that are different from either supercapacitors or rechargeable batteries in terms of fundamental principles and technological prospects. Since the generic term 'supercapattery' was initially proposed in an industrial EES project initiated in 2007, researchers have actively promoted its use, leading to its gradual recognition by the EES community [19-24].

Supercapatteries represent various hybrid EES devices that take advantage of both capacitive and non-capacitive Faradaic (or Nernstian) charge storage mechanisms at either the electrode material level or the device level. For example, Li-ion capacitors possess both a Li-ion battery electrode that can provide non-capacitive Faradaic charge storage and a supercapacitor electrode that can provide capacitive charge storage, meaning that Li-ion capacitors cannot be regarded as a capacitor because of the noncapacitive Faradaic charge storage in the cell nor as a rechargeable battery because of its capacitive behaviour. This is also the case with Na-ion capacitors. Therefore, 'supercapattery' as a generic term can be used to describe all devices consisting of a battery electrode and a capacitive electrode such as Li-ion capacitors, Na-ion capacitors and other hybrid EES devices that combine the merits of both capacitive and non-capacitive Faradaic charge storage mechanisms.

Various comprehensive reviews on supercapacitors and supercapatteries as well as critical reviews on electrode materials, electrolytes and engineering fundamentals of supercapatteries have been published in the past 3 years [25-30]. This review, however, intends to introduce the fundamentals of supercapatteries and present recent progress in supercapattery development in terms of electrode and electrolyte materials, device design and engineering and performance advantages and limitations.

\section{Fundamentals of Supercapatteries}

Supercapatteries can exhibit capacitive performances similar to conventional capacitors including rectangular cyclic voltammograms (CVs) and linear galvanic charge and discharge plots (GCDs). Because of this, the fundamentals of conventional capacitors can also be applied to supercapatteries in which capacitance $(C)$ is the proportionality between the stored charge $(q)$ and the voltage $(U)$ applied across a capacitor. This proportionality is also equal to the ratio of the stored charge change $(\Delta q)$ to the voltage variation $(\Delta U)$ as the voltage of a capacitor is scanned at a constant voltage scan rate $(v=\mathrm{d} U / \mathrm{d} t)$ in CVs. Because current (i) flowing through a capacitor is proportional to $v$, this proportionality is also equal to capacitance as described in Eq. (1).

$C=\frac{\Delta q}{\Delta U}=\frac{\mathrm{d} q / \mathrm{d} t}{\mathrm{~d} U / \mathrm{d} t}=\frac{i}{v}$

For example, the $\mathrm{CV}$ of an ideal capacitor as derived from Eq. (1) is $50 \mathrm{mF}$ with a $U_{\max }$ of $5 \mathrm{~V}$ (Fig. 1a). In addition, because current at a voltage scan rate remains constant, but current polarity (positive or negative) follows the voltage scan direction (Eq. 1), rectangular-shaped CVs are obtained with sharp current shifts at both ends of the voltage scan. Therefore, CVs can be used to evaluate the capacitive performance of EES devices such as electrical double-layer capacitors (EDLCs), pseudocapacitors and supercapatteries. Furthermore, the CVs of these capacitive EES devices may distort slightly due to the slow kinetics of electrode reactions. Despite this, the ratios of $i / v$ or $\Delta q / \Delta U$ of these devices will remain constant and equal to the capacitance.

Ideal capacitors can also be charged and discharged at constant currents and exhibit triangular GCD plots (Fig. 1b) in which as these capacitors are charged, $U$ will 
Fig. 1 a CVs at indicated cell voltage scan rates and $\mathbf{b}$ GCD plots at indicated constant currents of a hypothetical conventional capacitor of $C=50$ $\mathrm{mF}$ with $U_{\max }=5 \mathrm{~V}$ derived from Eq. (1) [27, 30, 31]. c Schematic illustration of the charge storage mechanism in an EDLC using Act-C electrodes. The enlarged view in the point cycle shows charge storage on a single carbon particle through ion adsorption at the carbonelectrolyte interface (i.e. EDL capacitance) [30]. CVs of $\mathbf{d}$ Act-C in $0.3 \mathrm{~mol} \mathrm{~L}^{-1} \mathrm{~K}_{2} \mathrm{SO}_{4}$ at $5 \mathrm{mV} \mathrm{s}^{-1}$ in different potential ranges and e a symmetrical cell with equal amounts of Act-C on each electrode and $0.3 \mathrm{~mol} \mathrm{~L}^{-1}$ $\mathrm{K}_{2} \mathrm{SO}_{4}$ as the electrolyte at $5 \mathrm{mV} \mathrm{s}^{-1}$ in decreasing voltage ranges [32]
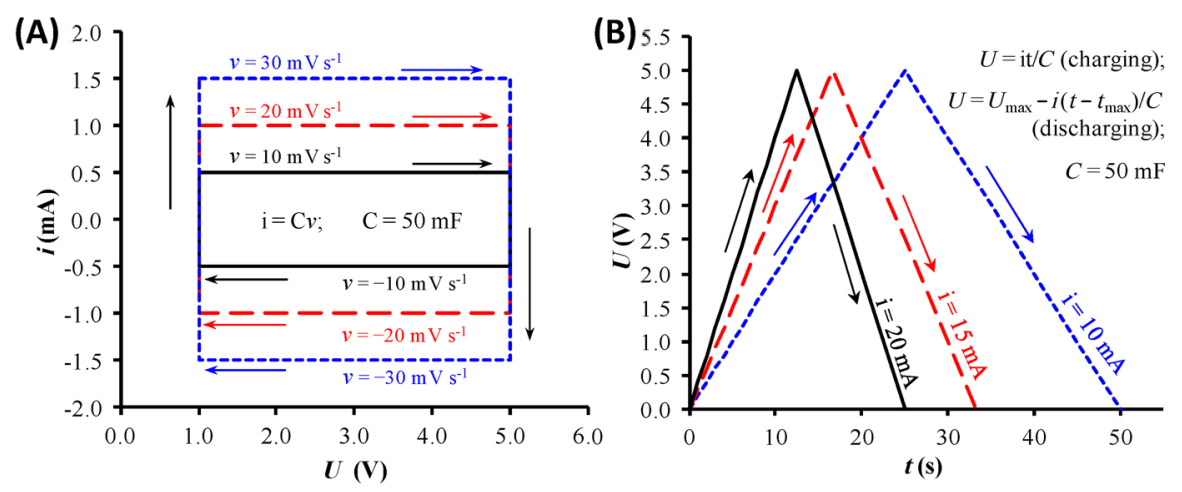

(C)

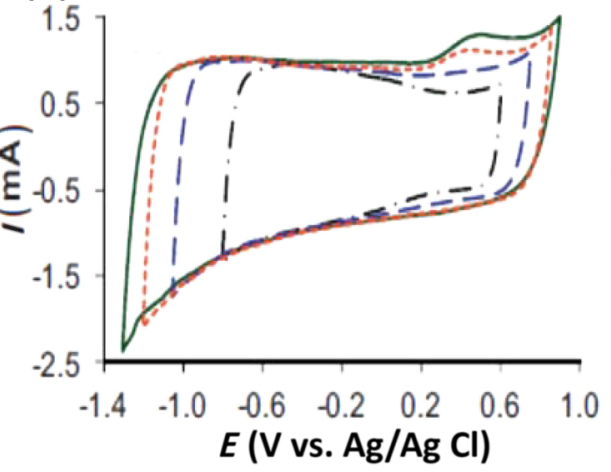

(E)

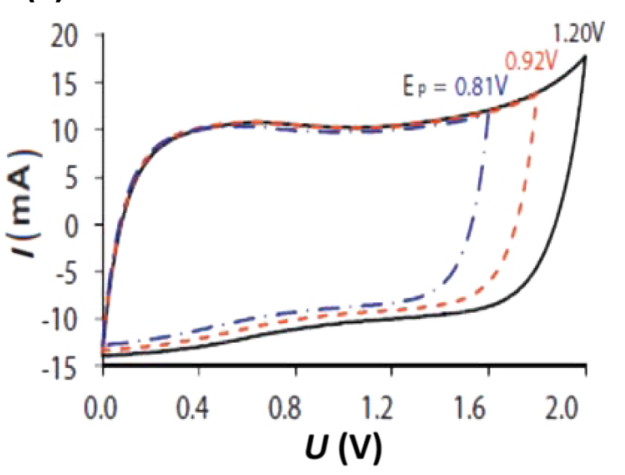

build up across the positive and negative electrodes. Here, Eq. (2) can be used to calculate the energy $(W)$ stored by a capacitor and indicates that $W$ is proportional to the capacitance of the cell $\left(C_{\text {cell }}\right)$ and the square of $\Delta U$.

$W=\frac{1}{2} C_{\text {cell }} \Delta U^{2}$

It should be noted that $W$ must be calculated through the integration of GCD plots in the discharge portion as described in Eq. (3) and is applicable to all EES devices, whereas Eq. (2) is a special case in which GCD plots in the discharge portion are linear (Fig. 1b).

$W=\int_{0}^{t} i U \mathrm{~d} t=i \int_{0}^{t} U \mathrm{~d} t$

Another important factor for capacitors is the maximum power output $\left(P_{\max }\right)$, which can only be reached if the working load resistance is equal to the equivalent series 
resistance (ESR) of a capacitor. Equation (4) shows the relationship between $P_{\max }, U$ and ESR.

$P_{\max }=\frac{U^{2}}{4 \mathrm{ESR}}$

Conventional capacitors usually possess small capacitances in the range of $10^{-6}-10^{-2} \mathrm{~F}$ such as the $50 \mathrm{mF}$ capacitance capacitor (Fig. 1a, b), meaning that even if $U$ can be charged to $100 \mathrm{~V}$, energy capacities can only reach $2500 \mathrm{~J}(\sim 0.7 \mathrm{Wh})$ for this capacitor. Alternatively, the capacitance of supercapacitors can easily reach greater than $100 \mathrm{~F}$. Despite these differences in capacitance, however, both capacitors and supercapacitors possess EDL charge storage mechanisms, and currently, the most widely used supercapacitor materials are high surface area activated carbons (Act-Cs) (Fig. 1c).

For example, Chae et al. [32] investigated Act-Cs as a supercapacitor electrode and reported that Act-Cs can retain rectangular $\mathrm{CVs}$ at different potential ranges (Fig. 1d),indicating an EDL storage mechanism in which as the potential range gradually extended, cathodic and anodic reactions appeared at $-1.1 \mathrm{~V}$ and $0.5 \mathrm{~V}$ versus $\mathrm{Ag} /$ $\mathrm{AgCl}$, respectively. Here, these researchers attributed the reduction reaction to $\mathrm{H}^{+}+\mathrm{e} \rightarrow \mathrm{H}_{\mathrm{ad}}$ in the micropores of Act-Cs and reported that the reductive potential was more negative than the theoretical negative potential limit for water $(-1.0 \mathrm{~V}$ vs. $\mathrm{Ag} / \mathrm{AgCl})$ [33], suggesting that such negative reductive potentials were mainly due to the overpotential of carbon-based materials. A small anodic current hump at $0.5 \mathrm{~V}$ (Fig. 1d) was also observed and was interpreted as evidence of the re-oxidation of produced $\mathrm{H}_{\mathrm{ad}}$ in the micropores of Act-Cs. These researchers also reported that as the potential range was further extended (more positive than $0.9 \mathrm{~V}$ vs. $\mathrm{Ag} / \mathrm{AgCl}$ ), a further oxidation current at potentials beyond $0.8 \mathrm{~V}$ was observed, which was attributed to the oxidation of water $\mathrm{H}_{2} \mathrm{O}=\mathrm{O}_{2}+4 \mathrm{H}^{+}+4 \mathrm{e}$ [34] and/or carbon $\mathrm{C}+\mathrm{H}_{2} \mathrm{O}=\mathrm{CO}_{2}+4 \mathrm{H}^{+}+4 \mathrm{e}$ [32]. Furthermore, the Act-Cs in this study exhibited satisfactory capacitive performances in both positive and negative potential scans between positive and negative limits in which a symmetrical supercapacitor with equal amounts of Act-Cs on each electrode was fabricated (Fig. 1e) and the obtained cell voltage easily reached $1.9 \mathrm{~V}$ or even higher due to the wide capacitive potential range of the Act-Cs in aqueous electrolytes.

In general, the specific capacitance of electrode materials $\left(C_{\mathrm{sp}}\right)$ can easily be derived from relevant CVs. By considering the fact that equal amounts of electrode materials $\left(m_{+}=m_{-}=m\right)$ are used to fabricate symmetrical supercapacitors, the specific capacitance and specific energy of cells $\left(C_{\text {sp,cell }}\right.$ and $W_{\mathrm{sp}}$ ) can be expressed as the ratios of $C_{\text {cell }}$ and $W$ to the total mass of the electrode material $\left(m_{+}+m_{-}=2 m\right)$, respectively, in which $C_{\mathrm{sp}, \text { cell }}=\frac{1}{2 m} C_{\text {cell }}=\frac{1}{4} C_{\mathrm{sp}}$ and $W_{\mathrm{sp}}=W / 2 m$. And by considering Eq. (2) in these relationships, $W_{\mathrm{sp}}$ can be rearranged as Eq. (5).

$W_{\mathrm{sp}}=\frac{\frac{1}{2} C_{\mathrm{cell}} \Delta U^{2}}{2 m}=\frac{1}{8} C_{\mathrm{sp}} \Delta U^{2}$

The above equations are also applicable to pseudocapacitors and supercapatteries, both of which exhibit rectangular CVs and linear GCD plots. Here, transition metal oxides (TMOs) and electronically conducting polymers (ECPs) have both been widely used as pseudocapacitive materials that can provide capacitive Faradaic charge storage from the transfer of delocalised valence electrons. Using metal clusters with different sizes as examples (Fig. 2a), the delocalisation of valence electrons corresponds to energy levels in which as more atoms are bound to clusters, orbits will split into more sub-orbits, leading to smaller energy gaps between the neighbouring energy levels of sub-orbits. And if the energy gap $\left(E_{\mathrm{g}}\right)$ between the lowest energy level of the higher energy group and the highest energy level of the lower energy group is large enough, all valence electrons will occupy the energy levels of the lower energy group, leaving higher energy levels empty, meaning that these valence electrons are localised at these lower energy levels. Here, if materials possessing these localised electrons are used to store charge, the Nernst equation (Eq. 6) [35] will govern reactions at a potential range near the equilibrium potential $E^{0}$, leading to current peaks on $\mathrm{CV}$ s and potential plateaus on GCD plots.

$E=E^{0}+\frac{n F}{R T} \ln \left(\frac{1-x}{x}\right)$

Here, $n$ is the number of electrons transferred, $F$ is the Faraday constant, $R$ is the gas constant, $T$ is the temperature, and $x$ is the mole fraction of the reduced species or sites. As an example of localised charge storage, Hu et al. [36] reported peak-shaped CVs from a non-conducting polymer, poly (o-aminophenol) ( $\mathrm{PoAP})$, with and without carbon nanotubes (CNTs) in an acidic electrolyte (Fig. 2b) in which $\mathrm{P} o \mathrm{AP}$ was non-conductive and can provide localised electrons for charge storage. In addition, TMOs and ECPs are semiconductors with delocalised electrons that can easily move between occupied and unoccupied orbits within valance bands (Fig. 2a) in which the difference of energy levels or potentials between neighbouring orbits is so small that every small potential variation will cause electron transfer, leading to constant currents with linear variations of potential in a capacitive manner the same as in EDLCs. Furthermore, Peng et al. [37] also reported that the polyaniline-CNT (PANI-CNT) composite, a type of 
Fig. 2 a Schematics of charge storage mechanisms based on localised and delocalised electrons and relevant split energy levels [27]. b Localised charge storage with peak-shaped CVs recorded from PoAP (red) and PoAP-CNT (blue) in $1 \mathrm{~mol} \mathrm{~L}^{-1}$ $\mathrm{HCl}$ at $10 \mathrm{mV} \mathrm{s}^{-1}$ [36]. c CVs of PANI-CNT composite recorded in the first and the 5000 th potential scan cycles in $1.0 \mathrm{~mol} \mathrm{~L}^{-1} \mathrm{HCl}$ at $100 \mathrm{mV} \mathrm{s}^{-1}$ [37]

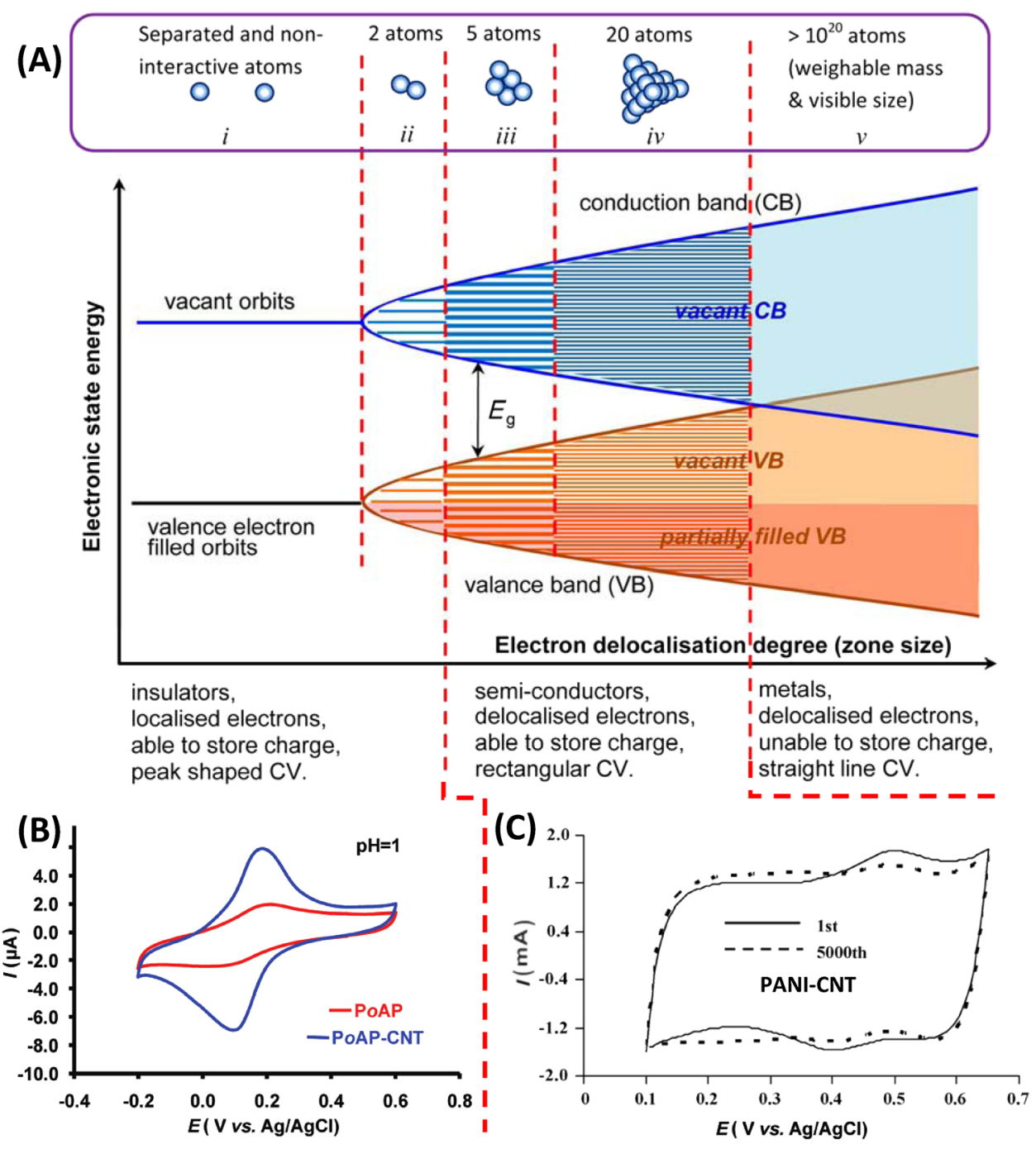

ECP composite, can demonstrate rectangular CVs within a capacitive potential range (Fig. $2 \mathrm{c}$ ).

In summary, three charge storage mechanisms exist in supercapatteries. The first mechanism involves EDL capacitance, which stores charge on electrode surfaces reversibly. The second mechanism is the Nernstian process, also called the non-capacitive Faradaic process, which broadly follows the Nernst equation describing the transfer of localised valence electrons. The third mechanism involves pseudocapacitance and is also called the capacitive Faradaic process, which proceeds in the capacitive pathway based on the transfer of delocalised valence electrons. Here, all three charge storage mechanisms can be applied to electrode materials for supercapatteries.

The specific energy of EDLCs has a strong relationship with the maximum charging voltage and specific capacitance. As for TMOs and ECPs, these are pseudocapacitive materials because of their semiconductor nature and possess higher specific capacitances than EDLCs but narrower potential ranges. Due to this, symmetrical devices composed of pseudocapacitive materials are not favourable for high energy capacity EES devices and various asymmetrical designs have been proposed to achieve high voltage. Currently, two main designs for asymmetrical devices exist in which one involves asymmetrical supercapacitors with positive and negative electrodes (the positrode: the positive electrode [24, 27, 38-43]; the negatrode: the negative electrode [24, 27, 39-44]) capable of capacitive charge storage typically through the permutation and combination of EDL and pseudocapacitive electrodes, whereas the other design involves hybrid configurations that combine supercapacitor electrodes with battery electrodes and have been reported under different names that mainly correspond to the different electrode materials used. Overall, the word 'hybrid' is not a suitable unified expression for the future development of these asymmetrical devices because it is too abstract, whereas the terms 'supercapattery' or 'supercabattery' are general enough to represent 
these asymmetrical devices vividly. And because supercapatteries take advantage of Faradaic charge storage in typical non-capacitive Faradaic storage, pseudocapacitors also fall in the scope of supercapatteries in a broad sense. And more often, supercapatteries contain electrodes with battery-type charge storage.

\section{Materials for Supercapatteries}

\subsection{Electrode Materials}

Electrode materials with EDL capacitance, pseudocapacitance or the Nernstian process can be utilised in supercapatteries in which different types of electrode materials will result in different supercapatteries. In order to comprehensively discuss these hybrid devices, several hypothetical supercapatteries were constructed by us [27] to illustrate their performance by using corresponding GCD plots one by one (Fig. 3a-d) and these hypothetical devices were
Fig. 3 Calculated GCD plots of positrodes (blue lines), negatrodes (black lines) and relevant cells (red dash lines): a a hypothetical pseudocapacitor with an Act-C negatrode and a pseudocapacitive positrode and a hypothetical supercapattery with a negatrode of $\mathrm{Li}$ metal or lithiated carbon and $\mathbf{b}$ an Act-C positrode or $\mathbf{c}$ a pseudocapacitive positrode [27]. d A hypothetical supercapattery with a typical battery-type negatrode and a pseudocapacitive positrode [27]. e Experimental demonstration of (a), (-) Act-C | KCl | PPy-CNT (+) [45]. f Experimental demonstration of (b), (-) $\mathrm{Li}\left|\mathrm{IL}+\mathrm{LiClO}_{4}\right|$ Act-C (+) [23]. g Experimental demonstration of $(\mathbf{c}),(-) \mathrm{Li} \mid \mathrm{PEO}-$ LiTFSI I LTAP | $1.0 \mathrm{M} \mathrm{LiCl}$ aq. I $\mathrm{MnO}_{2}(+)$ [12] (Reproduced with permission from Ref. [12]; permission conveyed through Copyright Clearance Center, Inc.). $\mathbf{h}$ Experimental demonstration of $(\mathbf{d}),(-) \mathrm{C}^{-\mathrm{MnO}_{y}}$ $\mathrm{CNT}\left|\mathrm{LiPF}_{6}\right| \mathrm{MnO}_{x}-\mathrm{CNT}(+)$ [22] (Reproduced with permission from Ref. [22]; permission conveyed through Copyright Clearance Center, Inc.)
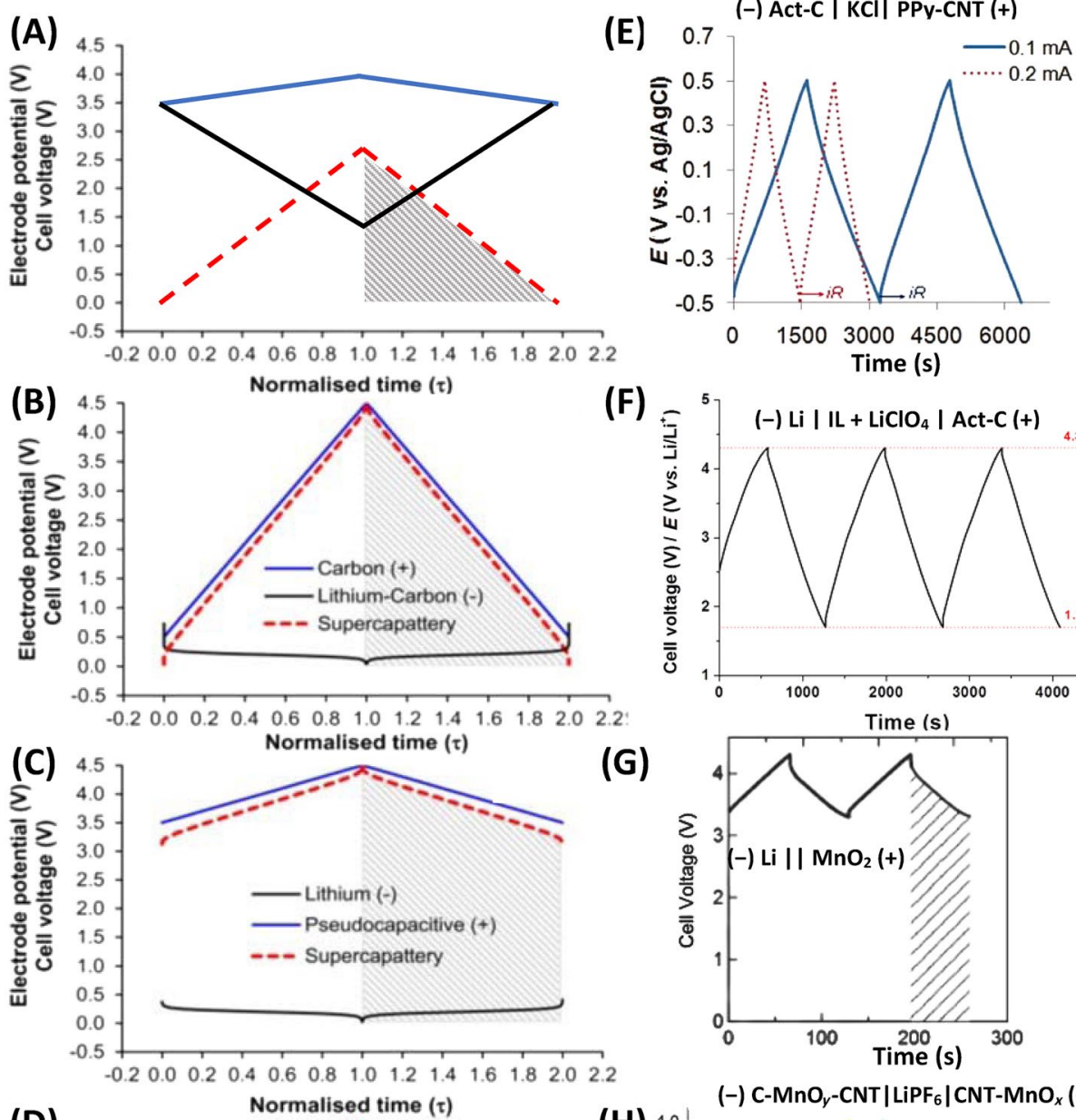

F)
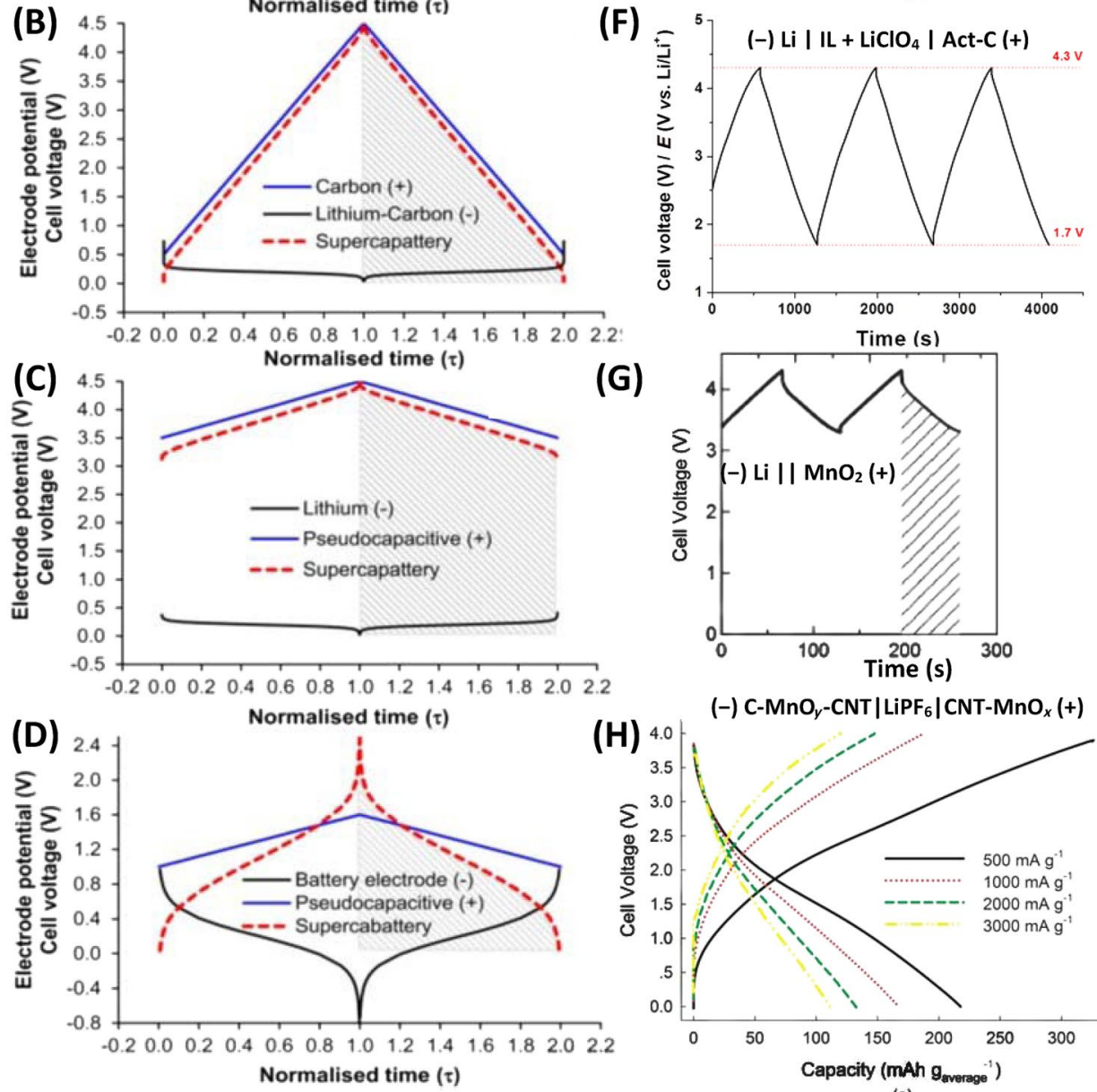

(-) C-MnO ${ }_{y}$-CNT $\left|\mathrm{LiPF}_{6}\right| \mathrm{CNT}-\mathrm{MnO}_{x}(+)$

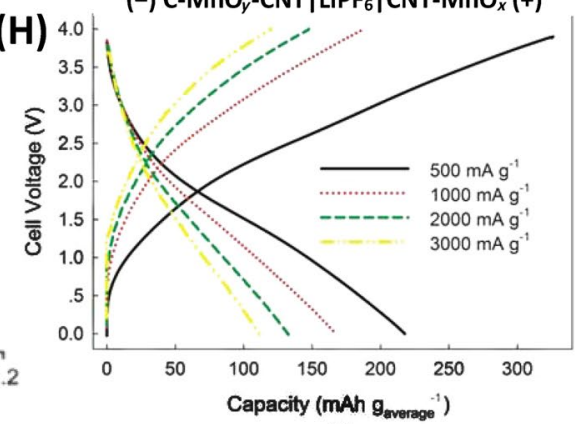

(a) 
confirmed by using relevant experimental data from the literature (Fig. 3e-h).

The first hypothetical supercapattery that was considered was a pseudocapacitor consisting of a pseudocapacitive positrode and an EDL capacitance negatrode. Here, the capacitive potential range of the pseudocapacitive positrode was relatively narrow (3.5-4.0 V), whereas the EDLC negatrode operated from 1.5 to $3.5 \mathrm{~V}$ to match the charge stored by the positrode with the predicted behaviour of the electrodes and the cell being demonstrated by GCD plots (Fig. 3a). And because the balance of electrode mass and charge is important for all EES devices, the amount of charge passing through the positrode must be equal to the charge passing through the negatrode in a supercapattery. Based on this, the mass, specific capacitance, voltage variation and amount of stored charge of positrodes and negatrodes must follow Eq. (7)

$q_{-}=m_{-} C_{\mathrm{sp}-} \Delta U_{-}=m_{+} C_{\mathrm{sp}+} \Delta U_{+}=q_{+}$

where $q$ represents the amount of charge passing through the electrode, $m$ is the mass of the electrode, and the subscripts - and + represent the negatrode and the positrodes, respectively. As for the hypothetical pseudocapacitive positrode and the EDLC positrode, $C_{\text {sp,pseudo }}$ of $500 \mathrm{~F} \mathrm{~g}^{-1}$ and $C_{\mathrm{sp}, \mathrm{EDLC}}$ of $200 \mathrm{~F} \mathrm{~g}^{-1}$ were hypothesis. Furthermore, by rearranging Eq. (7) and using available values, the mass ratio of the positrode to the negatrode in the hypothetical pseudocapacitor was calculated to be $m_{\text {pseudo }} / m_{\text {EDLC }}=C_{\text {sp,EDLC }} \Delta U_{-} / C_{\text {sp,pseudo }} \Delta U_{+}=\frac{500 \times 0.5}{200 \times 2}=0.625$ with $C=1 / 2 \times(1 /(0.625 \times 500)+1 / 200)=61 \mathrm{Fg}^{-1}$. Equation (5) can also be applied to calculate the specific energy of this hypothetical pseudocapacitor because the performance of the hypothetical cell is capacitive, leading to a value of $53 \mathrm{Wh} \mathrm{kg}^{-1}$, which is higher than values obtained from a symmetrical EDLC $\left(W_{\text {sp.sym }}=43 \mathrm{Wh} \mathrm{kg}^{-1}\right)$ with the same $\Delta U$.

Another hypothetical supercapattery hypothesised in this study was a common supercapattery possessing a Li metal negatrode and an Act-C positrode. Here, based on the behaviour of the electrodes and the cell as shown by GCD plots (Fig. 3b), the behaviour of this hypothetical cell was highly capacitive, meaning that Eq. (5) can be used to calculate the corresponding energy capacity. The minimum potential of the Act-C positrode was also set to $0.5 \mathrm{~V}$ vs. $\mathrm{Li} / \mathrm{Li}^{+}$to prevent the lithiation of the Act-C electrode during discharge. Furthermore, the mass of the positrode and the negatrode in this hypothetical supercapattery can be represented based on the charge passing through based on Eq. (8)

$Q_{-}=m_{-} Q_{\mathrm{sp}-}=m_{+} C_{\mathrm{sp}+} \Delta E_{+}=Q_{+}$

Here, $Q_{\text {sp }, \mathrm{Li}}=n F / M_{\mathrm{Li}}=13900 \mathrm{C} \mathrm{g}^{-1}=3861 \mathrm{mAh} \mathrm{g}^{-1}$ for the Li metal negatrode in which $n=1, F=96485 \mathrm{C} \mathrm{mol}^{-1}$ and $M_{\mathrm{Li}}=6.941 \mathrm{~g} \mathrm{~mol}^{-1}$, whereas for the Act-C positrode, $C_{\mathrm{sp}, \mathrm{C}}=200 \mathrm{~F} \mathrm{~g}^{-1}$ and $\Delta U=4.0 \mathrm{~V}$ were hypothesised. And by taking into account all of the data in Eq. (8), the mass ratio of the positrode to the negatrode can be calculated to be $m_{\mathrm{C}} / m_{\mathrm{Li}}=Q_{\mathrm{sp}, \mathrm{Li}} / C_{\mathrm{sp}, \mathrm{C}} \Delta E=\frac{13900}{200 \times 4.0}=17.4$. And because the ratio was so high, the mass of the Li metal negatrode was negligible as compared with that of the Act-C positrode in the supercapattery, whose capacitance value was approximately equal to the capacitance value of the Act- $\mathrm{C}$ positrode. Furthermore, because the minimum potential of the Act-C electrode was set to $0.5 \mathrm{~V}$ versus $\mathrm{Li} / \mathrm{Li}^{+}$instead of zero, then $\Delta U^{2}=(4.5 \mathrm{~V})^{2}-(0.5 \mathrm{~V})^{2}$. Moreover, according to Eq. (5), the above data lead to $W_{\mathrm{sp}}=555.6 \mathrm{Wh} \mathrm{kg}^{-1}$, which was much higher than that of the pseudocapacitor.

Another hypothetical supercapattery was constructed by replacing an EDLC positrode with a pseudocapacitive electrode (Fig. 3c) in which the specific capacitance of the pseudocapacitor electrode was assumed to be $500 \mathrm{~F} \mathrm{~g}^{-1}$ and the potential range of $\Delta E$ was assumed to be $1.0 \mathrm{~V}$ because pseudocapacitive materials are perceived to possess high specific capacitance and narrow potential range. Based on this, the mass ratio was calculated to be $m_{\mathrm{C}} / m_{\mathrm{Li}}=Q_{\mathrm{sp}, \mathrm{Li}} / C_{\mathrm{sp}, \mathrm{C}} \Delta E=\frac{13900}{500 \times 1.0}=27.8$, again indicating that the mass of the negatrode was negligible in the supercapattery. Similarly, by using $C_{\mathrm{sp}, \text { cell }} \approx C_{\mathrm{sp}, \mathrm{C}}=500 \mathrm{~F} \mathrm{~g}^{-1}$, $U_{\max }=4.5 \mathrm{~V}$ and $U_{\min }=3.5 \mathrm{~V}$ in Eq. (5), the specific energy of this hypothetic cell was calculated to be $555.6 \mathrm{Wh} \mathrm{kg}^{-1}$, which is equal to the value of the previous hypothetical supercapattery. Here, because Li metal electrodes work reversibly at negative potentials (Fig. 3b, c), sluggish curves can commonly be observed in the GCD plots of most battery electrodes (Fig. 3d). And because this hypothetical device consisted of a pseudocapacitance positrode and a battery negatrode, the battery negatrode charged/discharged at a more positive potential and the corresponding GCD plot was more sluggish as compared with the Li metal negatrode. In addition, the GCD plot of this hypothetical device was not linear in either the charge or the discharge portion, meaning that the performance of this device was not capacitive. As a result, the GCD of the cell was integrated to evaluate the cell energy capacity by using Eq. (3) instead of Eq. (2). Moreover, the shadowed area under the discharge branch of the GCD plots was proportional to the energy capacity of the cell in which the GCD plot (Fig. 3d) was more like that of a battery, meaning that the term 'supercabattery' is more appropriate for this hypothetical device.

Experimentally (Fig. 3e-h), Zhou et al. [45] reported that a supercapattery consisting of a polypyrrole-CNT (PPy-CNT) composite positrode, an Act-C negatrode and a $3 \mathrm{~mol} \mathrm{~L}^{-1} \mathrm{KCl}$ electrolyte can exhibit typical capacitive behaviours (Fig. 3e). Furthermore, Yu et al. [23] successfully demonstrated another supercapattery consisting of an Act-C positrode and a $\mathrm{Li} / \mathrm{Li}^{+}$negatrode in an ionic liquid 
(IL) electrolyte consisting of 1-butyl-1-methylpyrrolidinium tri(pentafluoroethyl)trifluorophosphate (BMPyrrFAP), gamma-butyrolactone ( $\gamma$-GBL) and $\mathrm{LiClO}_{4}$ and reported that the IL solution not only provided cations and anions for non-Faradic capacitive storage at the Act-C surface, but also enabled $\mathrm{Li} / \mathrm{Li}^{+}$redox reactions on the negatrode for noncapacitive Faradic or Nernstian storage. In addition, these researchers reported that the GCD plot of this supercapattery demonstrated typical capacitive GCD features (Fig. 3f) and that the resulting specific energy reached $230 \mathrm{Wh} \mathrm{kg}^{-1}$ at $1 \mathrm{~mA} \mathrm{~cm}^{-2}$ (based on active materials), which is the highest recorded for supercapatteries consisting of Act-C electrode materials. Makino et al. [12] also investigated a cell composed of (-) Li | PEO-LiTFSI | LTAP | $1.0 \mathrm{~mol} \mathrm{~L}^{-1} \mathrm{LiCl}$ $\left(60{ }^{\circ} \mathrm{C}\right) \mid \mathrm{MnO}_{2}(+)$ in which PEO-LiTFSI acted as a buffer layer and LTAP as a solid electrolyte made of LISICONtype solid glass ceramics. Here, the obtained GCD plot (Fig. 3g) was similar to the calculated hypothetical GCD plot (Fig. 3c), indicating the validity of the hypothetical cells and corresponding equations. Furthermore, Zhou et al. [22] experimented on a typical supercabattery composed of $\mathrm{MnO}_{x}$-CNT composites (Fig. 3h) and reported calculated specific energy of $208.6 \mathrm{Wh} \mathrm{kg}^{-1}$ using Eq. (3), of which $105.8 \mathrm{Wh} \mathrm{kg}^{-1}$ remained under ultrahigh specific power of $3000 \mathrm{~W} \mathrm{~kg}^{-1}$.

Based on these experimental studies, pseudocapacitive materials composed of TMO and ECP composites can play vital roles in the engineering of electrode materials for supercapatteries. Here, researchers have reported that CNTs are suitable for the construction of these composites in situations requiring porous structures for the transportation of charge balancing ions. Furthermore, CNTs possess high electrical conductivity and can therefore improve the electrical conductivity of composites. For example, Jin et al. [46] studied the two-stage progress of $\mathrm{MnO}_{2}$ redox deposition on CNTs due to the effects of nanoscaled micro-electrochemical cells. Here, these researchers reported that at the beginning stage of the redox deposition (Fig. 4a), $\mathrm{MnO}_{2}$ precipitation can only be found at or near the defect sites of CNTs as evidenced by TEM images of the $\mathrm{MnO}_{2}$-CNT composite (Fig. 4c) and that at a later stage (Fig. 4b), the electrically conductive CNTs created defects and other locations on the CNT wall as the anode and the cathode, respectively. These researchers also suggested that electron transfer in the microelectrochemical cell can promote the growth of $\mathrm{MnO}_{2}$ away from defects (e.g. inside the cavity of CNTs, Fig. 4d) and that this mechanism not only applies to $\mathrm{MnO}_{2}$-CNT composites, but also applies to composites of various TMOs and other carbon-based nanomaterials such as graphene and silicon carbide.

\subsection{Electrolytes}

Electrolytes are an indispensable component in all types of EES devices and allow for the transportation of ions to achieve ionic conductivity and the maintenance of electronic insulation between positrodes and negatrodes. In the case of supercapatteries, electrolytes also provide redox ions for electrode reactions (Fig. 2). More recently, electrolytes with additional redox species have attracted increasing attention because these redox electrolytes in supercapatteries can significantly enhance energy capacity [24, 47-49].

As an example of an IL electrolyte comprising of bi-redox species for the enhancement of supercapattery energy capacities, Mourad et al. [50] mixed an IL composed of 1-butyl3-methylimidazolium bis(trifluoromethylsulfonyl)imide (BMI-TFSI) with another bi-redox IL composed of the perfluorosulfonate anion bearing anthraquinone (AQ-PFS ${ }^{-}$) and the methyl imidazolium cation bearing 2,2,6,6-tetramethylpiperidinyl-1-oxyl (TEMPO-MI ${ }^{+}$) and used this IL mixture (Fig. 5a) as the electrolyte in a capacitive EES device composed of EDCL electrodes. Here, these researchers postulated that the cations and anions in the BMI-TFSI can be drawn into the negatrode and the positrode, respectively, and be adsorbed on carbon surfaces without invoking any Faradaic reactions during supercapacitor charging. Alternatively, these researchers also suggested that as the redoxactive $\mathrm{AQ}^{-\mathrm{PFS}^{-}}$and TEMPO-MI ${ }^{+}$are electro-adsorbed on the surface of EDLC electrodes, redox species will undergo fast Faradaic reactions. Serious self-discharging can occur in EES devices if redox species are dissolved in electrolytes, especially for electrolytes in supercapacitors. However, in the case of the mixture of bi-redox IL and BMI-TFSI, this issue appeared to have been avoided by the bulky size and high viscosity of the IL. Mourad et al. [50] in the same study also used Act-Cs (from PICA) and the bi-redox IL to fabricate a supercapacitor and studied the CVs of the carbon-based symmetrical supercapacitor with $0.5 \mathrm{~mol} \mathrm{~L}^{-1}$ $\mathrm{AQ}^{-\mathrm{PFS}^{-}}$and TEMPO-MI ${ }^{+}$in BMI-TFSI as compared with neat BMI-TFSI at $5 \mathrm{mV} \mathrm{s}^{-1}$ (Fig. 5b). And because micropores and mesopores in PICA can restrict access for IL ions, these researchers reported that the current amplitude in the $\mathrm{CVs}$ of the resulting supercapacitor doubled as the electrolyte changed from BMI-TFSI to the $0.5 \mathrm{~mol} \mathrm{~L}^{-1}$ bi-redox $\mathrm{IL}$. These researchers also reported that the broad oxidation and reduction peaks in the CVs appeared at intermediate voltages and attributed this to the redox processes of the bi-redox IL in the supercapacitor.

Akinwolemiwa et al. [24] recently also conducted another study into redox electrolytes in which the electrochemical behaviour of dissolved redox species in electrolytes and supercapattery features from the standpoint of Act-C electrode EDL capacitance was investigated. Here, based on the CVs and GCD plots of an equal electrode mass bi-electrolyte 
Fig. 4 Schematics of the redox deposition of $\mathrm{MnO}_{2}$ on CNTs in two stages: a Stage 1: direct redox deposition of $\mathrm{MnO}_{2}$ near the defect on CNTs. b Stage

2: nanoscale micro-electrochemical cell-induced cathodic reaction to further grow a coating of $\mathrm{MnO}_{2}$ on the external or the internal surface of CNTs. TEM images of $\mathbf{c}$ crystalline $\mathrm{MnO}_{2}$ coating on a CNT and $\mathbf{d}$ the cavity of a CNT filled with crystalline $\mathrm{MnO}_{2}$ [46]

\section{(A)}

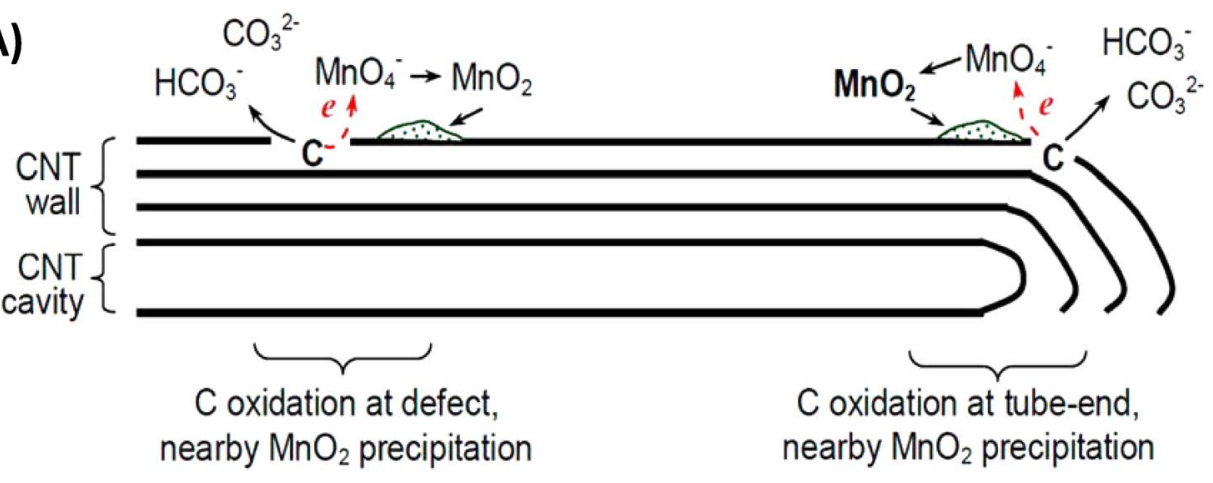

Redox reaction: $4 \mathrm{KMnO}_{4}+3 \mathrm{C}+\mathrm{H}_{2} \mathrm{O} \rightleftharpoons 4 \mathrm{MnO}_{2}+\mathrm{K}_{2} \mathrm{CO}_{3}+2 \mathrm{KHCO}_{3}$

(B)

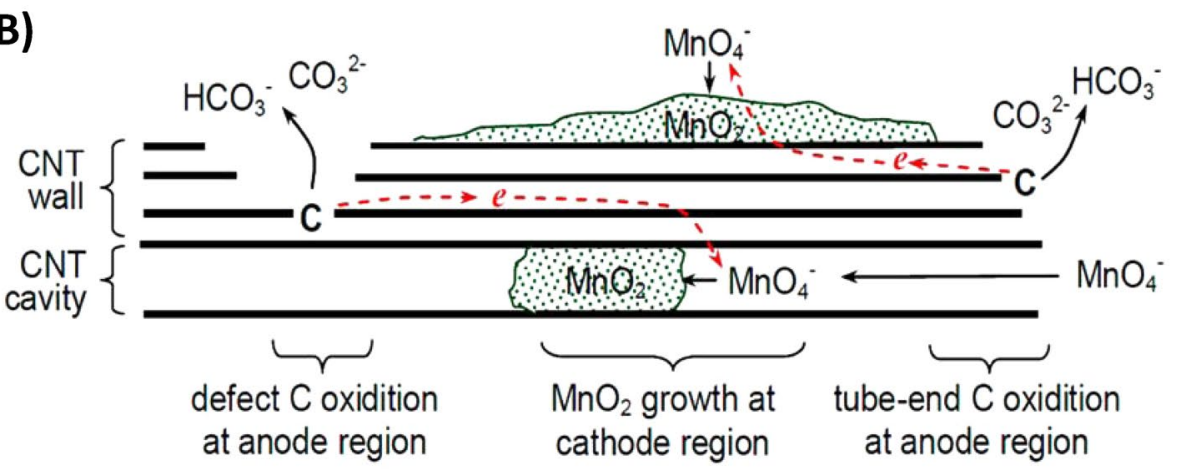

$\begin{array}{ll}\text { Anode (oxidation): } & 3 \mathrm{C}+16 \mathrm{OH}^{-} \rightleftharpoons 2 \mathrm{HCO}_{3}{ }^{-}+\mathrm{CO}_{3}{ }^{2-}+7 \mathrm{H}_{2} \mathrm{O}+12 e \\ \text { Cathode (reduction): } & 4 \mathrm{MnO}_{4}{ }^{-}+8 \mathrm{H}_{2} \mathrm{O}+12 e \rightleftharpoons 4 \mathrm{MnO}_{2}+16 \mathrm{OH}^{-}\end{array}$

Overall cell reaction: $4 \mathrm{KMnO}_{4}+3 \mathrm{C}+\mathrm{H}_{2} \mathrm{O} \rightleftharpoons 4 \mathrm{MnO}_{2}+\mathrm{K}_{2} \mathrm{CO}_{3}+2 \mathrm{KHCO}_{3}$

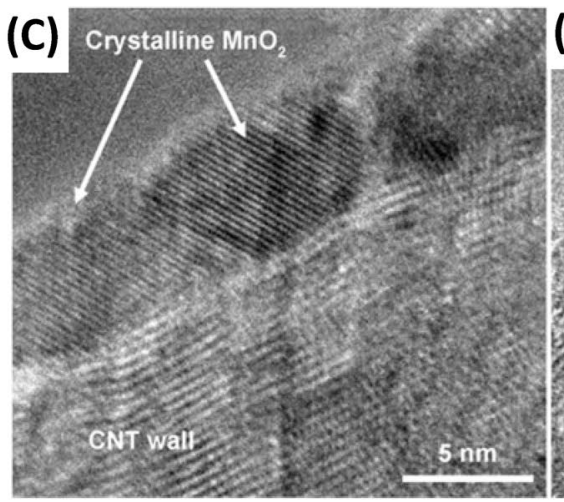

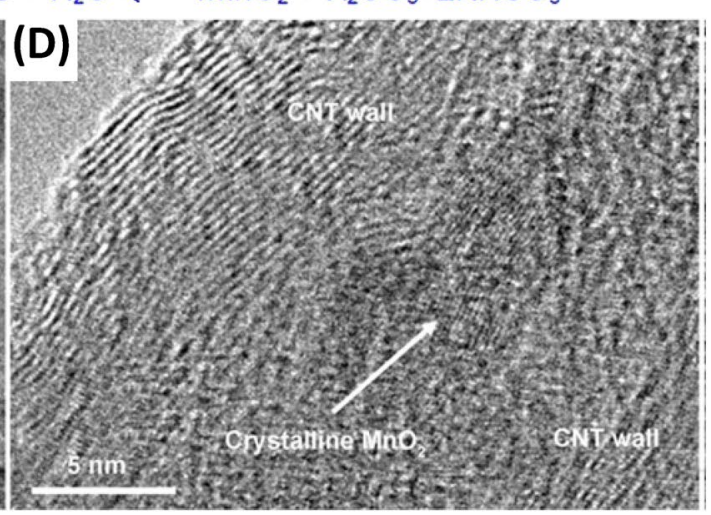

cell (-) Act-C | $2.0 \mathrm{~mol} \mathrm{~L}^{-1} \mathrm{KOH} \| 2.0 \mathrm{~mol} \mathrm{~L}^{-1} \mathrm{KI} \mid$ Act-C (+) (Fig. 6a, b), these researchers reported that the CV current flow increased at high cell voltages from 0.8 to $1.5 \mathrm{~V}$ and that the redox reaction of KI did not contribute to charge storage in the negatrode, demonstrating a method to achieve current peaks at high cell voltages in supercapatteries with dissolved redox species.
In summary, dissolved redox species such as the bi-redox IL and KI can increase the energy capacity of supercapatteries by storing significant amounts of charge and by retaining redox species in electrode pores or near electrodes. A more detailed discussion concerning the contribution of dissolved redox species in electrolytes to energy capacity can be found in a previous review [47]. 

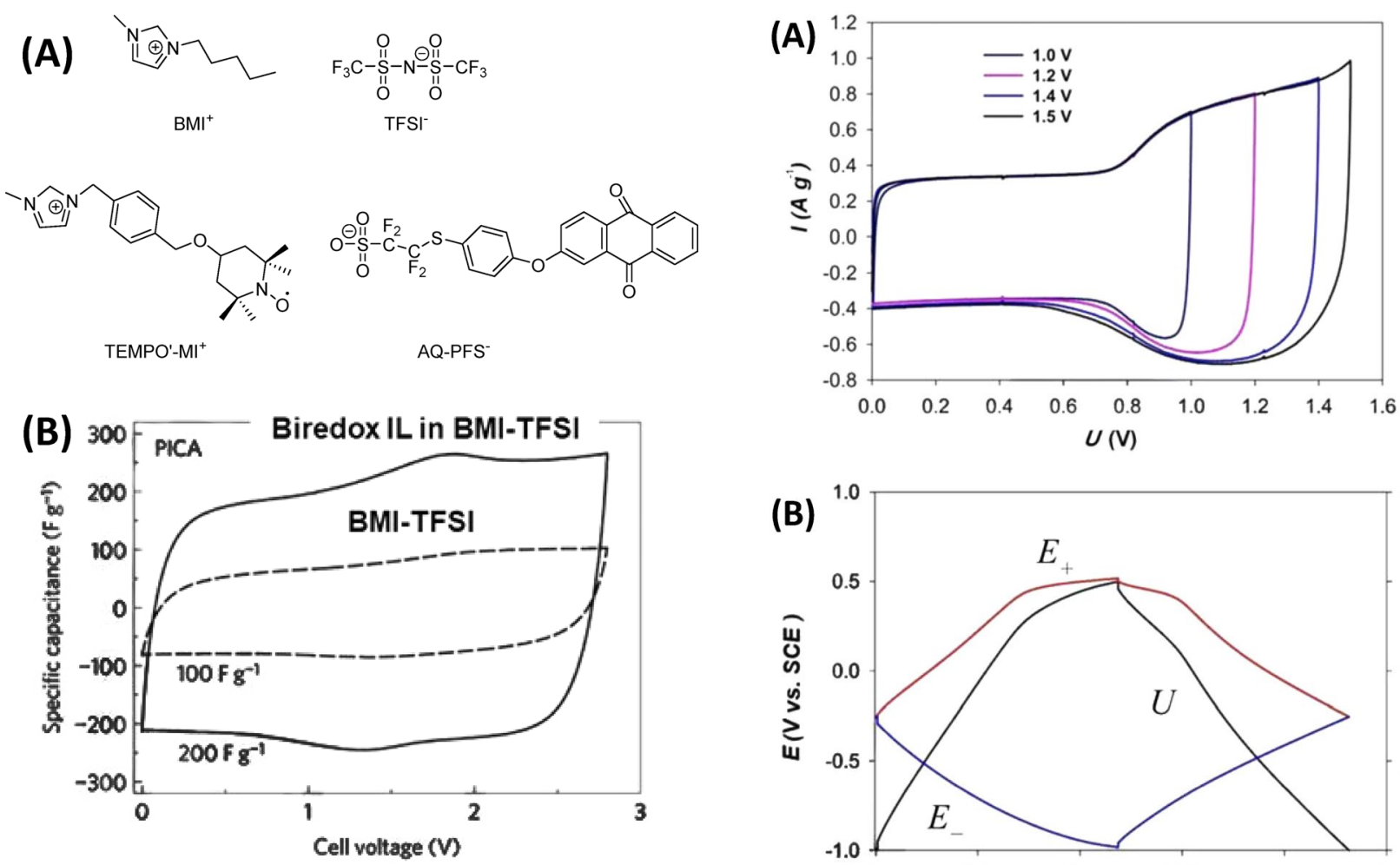

Fig. 5 a Molecular structures of BMI-TFSI and the bi-redox IL with the anthraquinone and 2,2,6,6-tetramethylpiperidinyl-1-oxyl group. b CVs of supercapacitors composed of PICA (Act-Cs) electrodes at $5 \mathrm{mV} \mathrm{s}^{-1}$ with the $0.5 \mathrm{~mol} \mathrm{~L}^{-1}$ bi-redox IL in BMI-TFSI (the solid line) and pure BMI-TFSI (the dashed line) [50].(Reproduced with permission from Ref. [50]. Copyright (C) 2016, Springer Nature)

\section{Device Engineering}

Electrode materials, especially TMO and ECP composites, are usually in the powder form unless electrodeposited on electrodes [51, 52]. Due to this, various methods have been applied to fabricate electrodes. For example, Zhou et al. [53] successfully screen-printed chemically synthesised ECPCNT composites onto titanium plates to produce supercapattery electrodes including stable ink and thick screen-printed Act-C and PPy-CNT electrodes (Fig. 7a-c) and assembled two pieces of the screen-printed electrodes into a supercapattery (Fig. 7d), resulting in high IR drops being observed in the obtained GCD plots (Fig. 7e). Here, these researchers used titanium plates because they can be used as both current collectors and bipolar plates to reduce the weight of stacks with multiple supercapatteries. And although the supercapattery in this study with the screen-printed electrodes operated properly, challenges for these screen-printed electrodes exist, including the lack of suitable current binders and surfactants for ink. This is because a high mass ratio of binders and surfactants needs to be added into the ink to

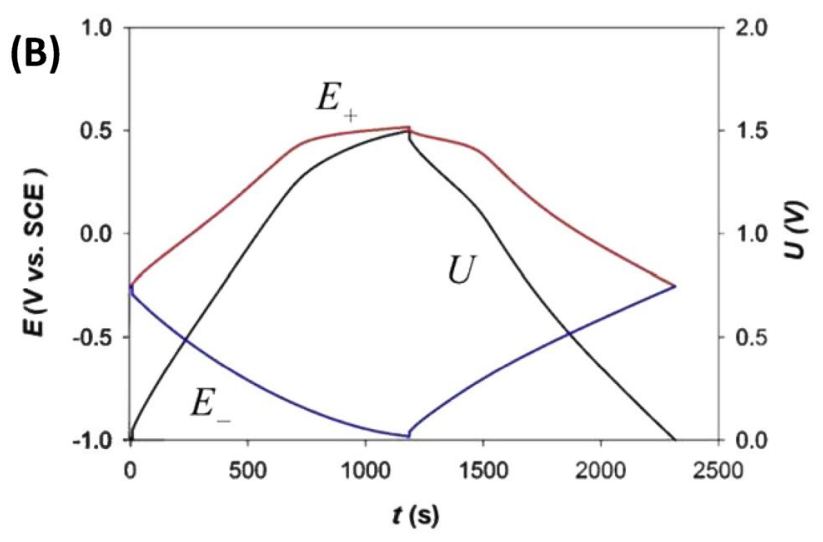

Fig. 6 a CVs of an equal electrode mass bi-electrolyte cell (-) Act-C | $2.0 \mathrm{~mol} \mathrm{~L}^{-1} \mathrm{KOH}$ || $2.0 \mathrm{~mol} \mathrm{~L}^{-1} \mathrm{KI}$ | Act-C (+) at $5.0 \mathrm{mV} \mathrm{s}^{-1}$ with different upper limits of cell voltage. b GCD plots of the same cell with a $1.5 \mathrm{~V}$ upper limit of cell voltage at $0.1 \mathrm{~A} \mathrm{~g}^{-1}$ [24]

produce strong, thick printed layers, which increases resistivity as compared with electro-co-deposited ECP-CNT composites. Furthermore, the thickness of screen-printed electrodes needs to be more adjustable. Another approach reported by researchers is to fabricate composite electrodes with fewer binders or without binders.

The bipolar stacking is another effective engineering design to fabricate supercapatteries in which neighbouring supercapattery cells are connected in series by bipolar plates in the stack (Fig. 8a), allowing almost half of the titanium plate to be removed as compared with ones fabricated by using external cable connections (required the titanium plate number: $n+1$ vs. $2 n, n=$ the number of the cells). As an example of the bipolar stacking, Zhou et al. [45] fabricated 19 single cells with the configuration of (-) $\mathrm{Ti}$ | CMPB | $0.5 \mathrm{~mol} \mathrm{~L}^{-1} \mathrm{KCl}$ | $\mathrm{PPy}-\mathrm{CNT}$ । $\mathrm{Ti}(+)$ in which $\mathrm{Ti}$ is the titanium bipolar plate and CMPB is Cabot Monarch 1300 pigment black, which is a specialty Act-C. Here, PPy-CNT composites were mixed with only $5 \mathrm{wt} \%$ polyvinyl alcohol as the binder in the positrode and the resulting GCD plots exhibited negligible IR drops at all GCD 
Fig. 7 Photographs of a the ink of the PPy-CNT composite, $\mathbf{b}$ the screen-printed electrode with Act-Cs on the titanium plate and $\mathbf{c}$ the screen-printed electrode with the PPy-CNT composite on the titanium plate. d Schematic of a unit cell with the screen-printed electrodes. e GCD plots of the unit cell at different currents [53]
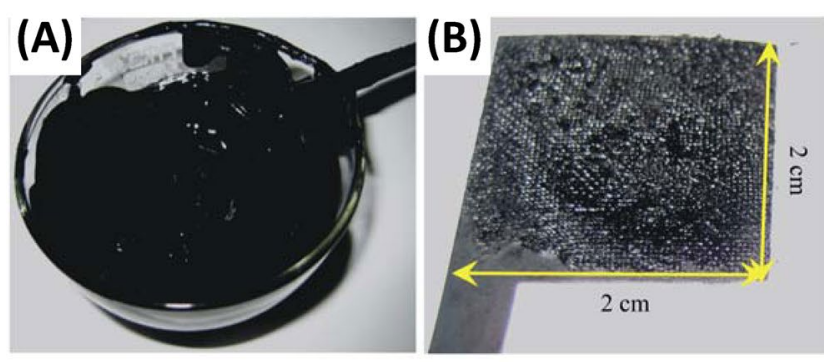

(C)
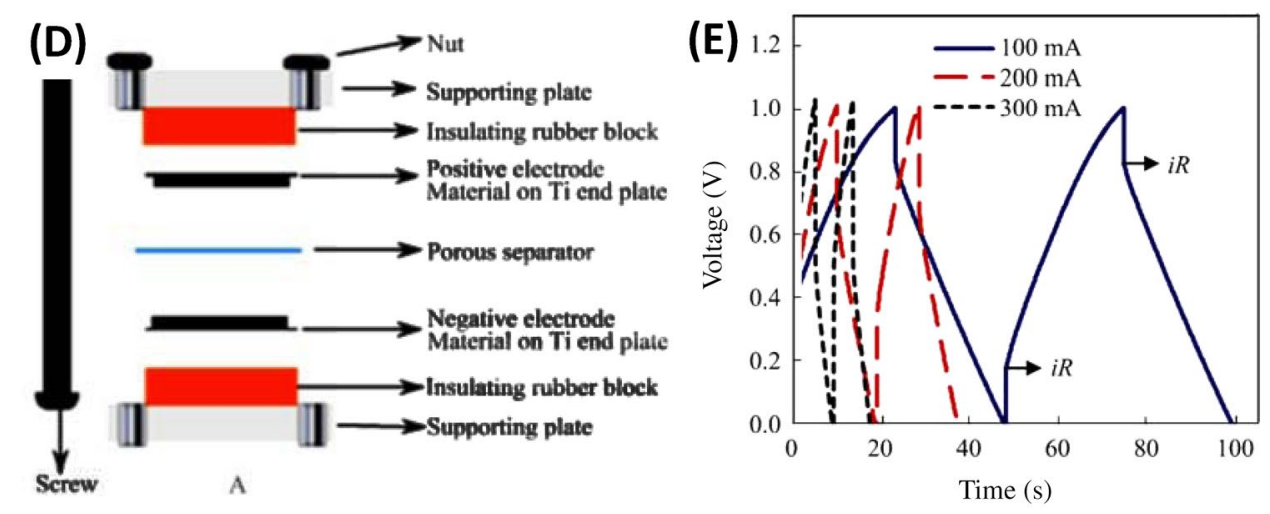

(A) a bipolar stack of 19 supercapatteries. b Corresponding GCD plots of the stack [45]

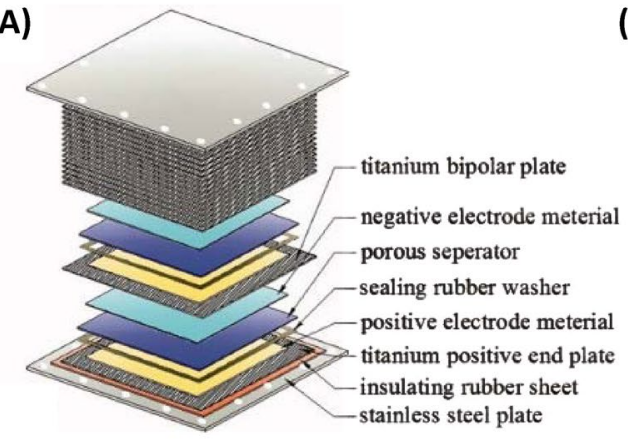

currents (Fig. 8b). These researchers also reported that the minimum ESR detected by electrochemical impedance spectroscopy was only $0.3 \mathrm{O}$ and that according to Eq. (4), $P_{\max }=\frac{U^{2}}{4 \mathrm{ESR}}=333 \mathrm{~W}$ or $24 \mathrm{~W} \mathrm{~g} \mathrm{~g}^{-1}$ against the total mass of the active materials.

And although laboratory demonstrations of the 19-cell stack have proven the feasibility of the bipolar stacking in scalable EES devices, the main concern of bipolar plates is the balance between plate weight and permeability. This is because permeability is directly related to plate material and thickness in which if bipolar plates were permeable to ions in electrolytes, internal short-circuiting can occur. To address this, Zhou et al. [45] used titanium bipolar plates ( $0.1 \mathrm{~mm}$ thickness) in their 19-cell stack to prevent this permeability. Evanko et al. [54] also recently investigated stackable bipolar pouch cells and suggested that lightweight carbon/polymer composite films can also be suitable as bipolar plates with a minimum thickness of $0.025 \mathrm{~mm}$ in which in their study, permeability testing was conducted on carbon black/polyethylene composite films and showed very low electrolyte permeability in a $\mathrm{HBr}$ solution for $72 \mathrm{~h}$. Alternatively, these researchers also reported that $\mathrm{HBr}$ can easily permeate through a 0.13 -mm-thick sheet of expanded graphite in acidic solutions.

Although bipolar stacking designs can effectively reduce the total weight of energy storage stacks, the ESR of stacked cells also needs to be carefully considered. This is because as EES cells are connected in series, their ESR will sum up in the stack. Because manufacture inconsistence is not uncommon, cells with high ESR in the stack can cause distorted GCDs, leading to serious performance degradation $[53,55,56]$. Here, researchers have suggested that stack designs involving parallel cells can minimise increased ESR and maintain output voltage as a single cell [56]. 
Table 1 Summary of different charge storage mechanisms* in supercapacitors, supercapatteries, supercabatteries and batteries along with corresponding performance metrics of representative cells by using different types of electrolytes (aq. $=$ the aqueous electrolyte, $\mathrm{IL}=$ the IL-based electrolyte, organic $=$ the organic electrolyte)

\begin{tabular}{|c|c|c|c|c|c|c|c|c|}
\hline \multirow[t]{3}{*}{ Device } & & \multicolumn{6}{|l|}{ Supercapattery } & \multirow{3}{*}{ Battery } \\
\hline & \multicolumn{3}{|l|}{ Supercapacitor } & \multicolumn{4}{|l|}{ Hybrid } & \\
\hline & EDLC & Pseudocapacit & & Capacitive hybr & & Others (superca & pattery) & \\
\hline $\begin{array}{l}\text { Electrode mate- } \\
\text { rial }\end{array}$ & NFCS + NFCS & NFCS + CFS & $\mathrm{CFS}+\mathrm{CFS}$ & NFCS + NCFS & $\mathrm{CFS}+\mathrm{NCFS}$ & $\mathrm{NFCS}+\mathrm{NCFS}$ & CFS + NCFS & $\mathrm{NCFS}+\mathrm{NCFS}$ \\
\hline $\begin{array}{l}\text { Specific energy } \\
\left(\mathrm{Wh} \mathrm{kg}^{-1}\right)\end{array}$ & $\begin{array}{l}102 \text { (IL), } 6.7 \\
\text { (aq.) }\end{array}$ & 3.6 & 26.6 & 230 & 261 & - & 208.6 & 250 \\
\hline $\begin{array}{l}\text { Max specific } \\
\text { power }\left(\mathrm{W} \mathrm{g}^{-1}\right)\end{array}$ & 111.6 & 24.7 & 13 & 59 & 25 & - & 3 & 1.5 \\
\hline $\begin{array}{l}\text { Cycling life } \\
\text { (cycles) }\end{array}$ & $>10000$ & $>5000$ & $>5000$ & $>1000$ & $>10000$ & - & $>1000$ & $<1200$ \\
\hline Electrolyte types & IL, aq. & aq. & aq. & IL & IL & - & Organic & Organic \\
\hline References & {$[57,58]$} & [45] & [19] & {$[23,59]$} & [60] & - & [22] & $* *$ \\
\hline
\end{tabular}

*NFCS: Non-Faradaic capacitive storage = electrical double-layer capacitance storage, CFS: capacitive Faradaic storage = pseudocapacitive storage, NCFS: non-capacitive faradaic storage = battery-type storage or Nernstian charge storage

**Data from web: https://en.wikipedia.org/wiki/Lithium-ion_battery\#cite_note-7

\section{Summary and Prospects of Supercapatteries}

'Supercapattery' is a generic term to describe a large group of hybrid EES devices that can combine the merits of rechargeable batteries with the merits of supercapacitors (Table 1). In these supercapatteries, three charge storage mechanisms can be applied to describe and compare the performance of electrode materials, including non-Faradaic capacitive storage (EDL capacitance), capacitive Faradaic storage (pseudocapacitive storage) and non-capacitive Faradaic storage (battery-type storage or Nernstian charge storage).In addition, because redox electrolytes can also contribute to the energy storage of EDLCs, such EDLCs also fall in the scope of supercapatteries. As for scalable supercapatteries, the selections of electrode materials and electrode fabrication methods are of equal importance in the performance of resulting devices in which the bipolar stacking with multiple supercapattery cells can achieve high energy density storage due to the reduction in almost half of the auxiliary materials (current collectors) if the permeability of the bipolar plates is ensured.

Overall, supercapatteries have attracted increasing attention in the EES community based on the increasing number of publications using the expression 'supercapattery', which is a more accurate generic term to define various EES hybrids that can balance energy capacity with power capability in one device. Here, the development of battery and supercapacitor materials can benefit the development of supercapatteries. In addition, novel engineering designs for supercapatteries such as the bipolar stacking are required to cross the gap between the laboratory setting and industrial manufacturing. Furthermore, more consideration needs to be given to the adaptive process for the manufacturing of supercapatteries using existing equipment for commercial batteries and supercapacitors.

Acknowledgements This work received funding from the Ningbo Municipal Government (3315 Plan and IAMET Special Fund, 2014A35001-1) and the Zhejiang Provincial Applied Research Programme for Commonweal Technology 2017C31104. Funding was provided by Engineering and Physical Sciences Research Council (Grant Nos. EP/J000582/1, GR/R68078).

Open Access This article is licensed under a Creative Commons Attribution 4.0 International License, which permits use, sharing, adaptation, distribution and reproduction in any medium or format, as long as you give appropriate credit to the original author(s) and the source, provide a link to the Creative Commons licence, and indicate if changes were made. The images or other third party material in this article are included in the article's Creative Commons licence, unless indicated otherwise in a credit line to the material. If material is not included in the article's Creative Commons licence and your intended use is not permitted by statutory regulation or exceeds the permitted use, you will need to obtain permission directly from the copyright holder. To view a copy of this licence, visit http://creativecommons.org/licenses/by/4.0/.

\section{References}

1. Larcher, D., Tarascon, J.M.: Towards greener and more sustainable batteries for electrical energy storage. Nat. Chem. 7, 19-29 (2015). https://doi.org/10.1038/nchem.2085

2. Shabangoli, Y., Rahmanifar, M.S., El-Kady, M.F., et al.: Thionine functionalized 3D graphene aerogel: combining simplicity and efficiency in fabrication of a metal-free redox supercapacitor. 
Adv. Energy Mater. 8, 1802869 (2018). https://doi.org/10.1002/ aenm.201802869

3. Shang, W., Liu, Y., Kim, E., et al.: Selective assembly and functionalization of miniaturized redox capacitor inside microdevices for microbial toxin and mammalian cell cytotoxicity analyses. Lab Chip 18, 3578-3587 (2018). https://doi.org/10.1039/c81c00583d

4. Byeon, A., Boota, M., Beidaghi, M., et al.: Effect of hydrogenation on performance of $\mathrm{TiO}_{2}(\mathrm{~B})$ nanowire for lithium ion capacitors. Electrochem. Commun. 60, 199-203 (2015). https://doi. org/10.1016/j.elecom.2015.09.004

5. Chen, Z.K., Lang, J.W., Liu, L.Y., et al.: Preparation of a NbN/ graphene nanocomposite by solution impregnation and its application in high-performance Li-ion hybrid capacitors. RSC Adv. 7, 19967-19975 (2017). https://doi.org/10.1039/c7ra01671a

6. Ma, Y., Chang, H., Zhang, M., et al.: Graphene-based materials for lithium-ion hybrid supercapacitors. Adv. Mater. 27, 5296-5308 (2015). https://doi.org/10.1002/adma.201501622

7. Shen, L., Lv, H., Chen, S., et al.: Peapod-like $\mathrm{Li}_{3} \mathrm{VO}_{4} / \mathrm{N}$-doped carbon nanowires with pseudocapacitive properties as advanced materials for high-energy lithium-ion capacitors. Adv. Mater. 29, 1700142 (2017). https://doi.org/10.1002/adma.201700142

8. Wang, H., Zhu, C., Chao, D., et al.: Nonaqueous hybrid lithiumion and sodium-ion capacitors. Adv. Mater. 29, 1702093 (2017). https://doi.org/10.1002/adma.201702093

9. Arnaiz, M., Gomez-Camer, J.L., Ajuria, J., et al.: High performance titanium antimonide TiSb2 alloy for Na-ion batteries and capacitors. Chem. Mater. 30, 8155-8163 (2018). https:// doi.org/10.1021/acs.chemmater.8b02639

10. Thangavel, R., Kaliyappan, K., Kim, D.U., et al.: All-organic sodium hybrid capacitor: a new, high-energy, high-power energy storage system bridging batteries and capacitors. Chem. Mater. 29, 7122-7130 (2017). https://doi.org/10.1021/acs.chemm ater.7b00841

11. Cherusseri, J., Sambath Kumar, K., Choudhary, N., et al.: Novel mesoporous electrode materials for symmetric, asymmetric and hybrid supercapacitors. Nanotechnology 30, 202001 (2019). https://doi.org/10.1088/1361-6528/ab0685

12. Makino, S., Shinohara, Y., Ban, T., et al.: $4 \mathrm{~V}$ class aqueous hybrid electrochemical capacitor with battery-like capacity. RSC Adv. 2, 12144-12147 (2012). https://doi.org/10.1039/ c2ra22265e

13. Rafai, S., Qiao, C., Naveed, M., et al.: Microwave-anion-exchange route to ultrathin cobalt-nickel-sulfide nanosheets for hybrid supercapacitors. Chem. Eng. J. 362, 576-587 (2019). https://doi. org/10.1016/j.cej.2019.01.059

14. Xie, L.Y., Zong, Q.J., Zhang, Q.C., et al.: Hierarchical NiCoP nanosheet arrays with enhanced electrochemical properties for high-performance wearable hybrid capacitors. J. Alloys Compd. 781, 783-789 (2019). https://doi.org/10.1016/j.jallc om.2018.12.067

15. Zuo, W., Li, R., Zhou, C., et al.: Battery-supercapacitor hybrid devices: recent progress and future prospects. Adv. Sci. 4, 1600539 (2017). https://doi.org/10.1002/advs.201600539

16. Li, H.B., Yu, M.H., Wang, F.X., et al.: Amorphous nickel hydroxide nanospheres with ultrahigh capacitance and energy density as electrochemical pseudocapacitor materials. Nat. Commun. 4, 1894 (2013). https://doi.org/10.1038/ncomms2932

17. Nam, K.W., Ma, S.B., Yoon, W.S., et al.: Novel concept of pseudocapacitor using stabilized lithium metal powder and non-lithiated metal oxide electrodes in organic electrolyte. Electrochem. Commun. 11, 1166-1169 (2009). https://doi.org/10.1016/j.eleco m.2009.03.038

18. Wu, C., Lu, X., Peng, L., et al.: Two-dimensional vanadyl phosphate ultrathin nanosheets for high energy density and flexible pseudocapacitors. Nat. Commun. 4, 2431 (2013). https://doi. org/10.1038/ncomms3431
19. Huang, Z.H., Song, Y., Xu, X.X., et al.: Ordered polypyrrole nanowire arrays grown on a carbon cloth substrate for a highperformance pseudocapacitor electrode. ACS Appl. Mater. Inter. 7, 25506-25513 (2015). https://doi.org/10.1021/acsami.5b08830

20. Peng, X., Chai, H., Cao, Y.L., et al.: Facile synthesis of costeffective $\mathrm{Ni}_{3}\left(\mathrm{PO}_{4}\right)_{2} \cdot 8 \mathrm{H}_{2} \mathrm{O}$ microstructures as a supercapattery electrode material. Mater. Today Energy 7, 129-135 (2018). https ://doi.org/10.1016/j.mtener.2017.12.004

21. Raj, S., Kar, P., Roy, P.: Facile synthesis of flower-like morphology $\mathrm{Cu}_{0.27} \mathrm{Co}_{2.73} \mathrm{O}_{4}$ for a high-performance supercapattery with extraordinary cycling stability. Chem. Commun. 54, 12400-12403 (2018). https://doi.org/10.1039/c8cc04625e

22. Zhou, H.T., Wang, X.H., Sheridan, H., et al.: Boosting the energy density of 3D dual-manganese oxides-based li-ion supercabattery by controlled mass ratio and charge injection. J. Electrochem. Soc. 163, A2618-A2622 (2016). https://doi.org/10.1149/2.0691613jes

23. Yu, L., Chen, G.Z.: High energy supercapattery with an ionic liquid solution of $\mathrm{LiClO}_{4}$. Faraday Discuss. 190, 231-240 (2016). https://doi.org/10.1039/c5fd00232j

24. Akinwolemiwa, B., Wei, C.H., Yang, Q.H., et al.: Optimal utilization of combined double layer and Nernstian charging of activated carbon electrodes in aqueous halide supercapattery through capacitance unequalization. J. Electrochem. Soc. 165, A4067-A4076 (2018). https://doi.org/10.1149/2.0031902jes

25. Akinwolemiwa, B., Chen, G.Z.: Fundamental consideration for electrochemical engineering of supercapattery. J. Braz. Chem. Soc. 29, 960-972 (2018). https://doi.org/10.21577/01035053.20180010

26. Xia, L., Yu, L.P., Hu, D., et al.: Electrolytes for electrochemical energy storage. Mater. Chem. Front. 1, 584-618 (2017). https:// doi.org/10.1039/c6qm00169f

27. Chen, G.Z.: Supercapacitor and supercapattery as emerging electrochemical energy stores. Int. Mater. Rev. 62, 173-202 (2017). https://doi.org/10.1080/09506608.2016.1240914

28. Akinwolemiwa, B., Wei, C.H., Chen, G.Z.: Mechanisms and designs of asymmetrical electrochemical capacitors. Electrochim. Acta 247, 344-357 (2017). https://doi.org/10.1016/j.elect acta.2017.06.088

29. Yu, L.P., Chen, G.Z.: Redox electrode materials for supercapatteries. J. Power Sources 326, 604-612 (2016). https://doi. org/10.1016/j.jpowsour.2016.04.095

30. Guan, L., Yu, L.P., Chen, G.Z.: Capacitive and non-capacitive faradaic charge storage. Electrochim. Acta 206, 464-478 (2016). https://doi.org/10.1016/j.electacta.2016.01.213

31. Chen, G.Z.: Understanding supercapacitors based on nanohybrid materials with interfacial conjugation. Progress Nat. Sci. Mater. Int. 23, 245-255 (2013). https://doi.org/10.1016/j. pnsc.2013.04.001

32. Chae, J.H., Chen, G.Z.: $1.9 \mathrm{~V}$ aqueous carbon-carbon supercapacitors with unequal electrode capacitances. Electrochim. Acta 86, 248-254 (2012). https://doi.org/10.1016/j.electacta.2012.07.033

33. Demarconnay, L., Raymundo-Piñero, E., Béguin, F.: A symmetric carbon/carbon supercapacitor operating at $1.6 \mathrm{~V}$ by using a neutral aqueous solution. Electrochem. Commun. 12, 1275-1278 (2010). https://doi.org/10.1016/j.elecom.2010.06.036

34. Khomenko, V., Raymundo-Piñero, E., Béguin, F.: Optimisation of an asymmetric manganese oxide/activated carbon capacitor working at $2 \mathrm{~V}$ in aqueous medium. J. Power Sources 153, 183-190 (2006). https://doi.org/10.1016/j.jpowsour.2005.03.210

35. Bard, A.J., Faulkner, L.R.: Electrochemical Methods: Fundamentals and Applications. Wiley, New York (2001)

36. Hu, D., Peng, C., Chen, G.Z.: Electrodeposition of nonconducting polymers: roles of carbon nanotubes in the process and products. ACS Nano 4, 4274-4282 (2010). https://doi.org/10.1021/nn100 $849 \mathrm{~d}$ 
37. Peng, C., Jin, J., Chen, G.Z.: A comparative study on electrochemical co-deposition and capacitance of composite films of conducting polymers and carbon nanotubes. Electrochim. Acta 53, 525-537 (2007). https://doi.org/10.1016/j.electacta.2007.07.004

38. Che, C.Y., Vagin, M., Ail, U., et al.: Twinning lignosulfonate with a conducting polymer via counter-ion exchange for large-scale electrical storage. Adv. Sustain. Syst. 3, 9 (2019). https://doi. org/10.1002/adsu.201900039

39. Lee, H.W., Shinde, N.M., Shinde, P.V., et al.: High energy and power density of self-grown $\mathrm{CuS} @ \mathrm{Cu}_{2} \mathrm{O}$ core-shell supercapattery positrode. J. Solid State Electrochem. 23, 2609-2617 (2019). https://doi.org/10.1007/s10008-019-04351-0

40. Priyadharsini, N., Shanmugavani, A., Surendran, S., et al.: Improved electrochemical performances of $\mathrm{LiMnPO}_{4}$ synthesized by a hydrothermal method for Li-ion supercapatteries. J. Mater. Sci. Mater. Electron. 29, 18553-18565 (2018). https://doi. org/10.1007/s10854-018-9972-5

41. Shinde, N.M., Xia, Q.X., Yun, J.M., et al.: Polycrystalline and Mesoporous 3- $\mathrm{D} \mathrm{Bi}_{2} \mathrm{O}_{3}$ nanostructured negatrodes for high-energy and power-asymmetric supercapacitors: superfast room-temperature direct wet chemical growth. ACS Appl. Mater. Inter. 10, 11037-11047 (2018). https://doi.org/10.1021/acsami.8b00260

42. Sun, X.W., Simonsen, S.C., Norby, T., et al.: Composite membranes for high temperature PEM fuel cells and electrolysers: a critical review. Membranes 9, 46 (2019). https://doi.org/10.3390/ membranes 9070083

43. Surendran, S., Shanmugapriya, S., Zhu, P., et al.: Hydrothermally synthesised NiCoP nanostructures and electrospun $\mathrm{N}$-doped carbon nanofiber as multifunctional potential electrode for hybrid water electrolyser and supercapatteries. Electrochim. Acta 296, 1083-1094 (2019). https://doi.org/10.1016/j.elect acta.2018.11.078

44. Xia, Q.X., Shinde, N.M., Zhang, T.F., et al.: Seawater electrolytemediated high volumetric MXene-based electrochemical symmetric supercapacitors. Dalton Trans. 47, 8676-8682 (2018). https:// doi.org/10.1039/c8dt01375f

45. Zhou, X.H., Peng, C., Chen, G.Z.: $20 \mathrm{~V}$ stack of aqueous supercapacitors with carbon (-), titanium bipolar plates and CNTpolypyrrole composite (+). AlChE J. 58, 974-983 (2012). https ://doi.org/10.1002/aic.12632

46. Jin, X., Zhou, W., Zhang, S., et al.: Nanoscale microelectrochemical cells on carbon nanotubes. Small 3, 1513-1517 (2007). https ://doi.org/10.1002/smll.200700139

47. Akinwolemiwa, B., Peng, C., Chen, G.Z.: Redox electrolytes in supercapacitors. J. Electrochem. Soc. 162, A5054-A5059 (2015). https://doi.org/10.1149/2.0111505jes

48. Evanko, B., Boettcher, S.W., Yoo, S.J., et al.: Redox-enhanced electrochemical capacitors: status, opportunity, and best practices for performance evaluation. ACS Energy Lett. 2, 2581-2590 (2017). https://doi.org/10.1021/acsenergylett.7b00828
49. Lee, J., Srimuk, P., Fleischmann, S., et al.: Redox-electrolytes for non-flow electrochemical energy storage: a critical review and best practice. Prog. Mater Sci. 101, 46-89 (2019). https://doi. org/10.1016/j.pmatsci.2018.10.005

50. Mourad, E., Coustan, L., Lannelongue, P., et al.: Biredox ionic liquids with solid-like redox density in the liquid state for highenergy supercapacitors. Nat. Mater. 16, 446-453 (2017). https:// doi.org/10.1038/nmat4808

51. Peng, C., Hu, D., Chen, G.Z.: Achieving low voltage half electrolysis with a supercapacitor electrode. Energy Environ. Sci. 7, 1018-1022 (2014). https://doi.org/10.1039/c3ee43817a

52. Peng, C., Snook, G.A., Fray, D.J., et al.: Carbon nanotube stabilised emulsions for electrochemical synthesis of porous nanocomposite coatings of poly[3,4-ethylene-dioxythiophene]. Chem. Commun. 44, 4629-4631 (2006). https://doi.org/10.1039/b6092 $93 \mathrm{~d}$

53. Zhou, X.H., Chen, G.Z.: Electrochemical performance of screenprinted composite coatings of conducting polymers and carbon nanotubes on titanium bipolar plates in aqueous asymmetrical supercapacitors. J. Electrochem. 18, 548-565 (2012)

54. Evanko, B., Yoo, S.J., Lipton, J., et al.: Stackable bipolar pouch cells with corrosion-resistant current collectors enable high-power aqueous electrochemical energy storage. Energy Environ. Sci. 11, 2865-2875 (2018). https://doi.org/10.1039/c8ee00546j

55. Kaipannan, S., Marappan, S.: Fabrication of $9.6 \mathrm{~V}$ high-performance asymmetric supercapacitors stack based on nickel hexacyanoferrate-derived $\mathrm{Ni}(\mathrm{OH})_{2}$ nanosheets and bio-derived activated carbon. Sci. Rep. 9, 1 (2019). https://doi.org/10.1038/s41598-01837566-8

56. Li, J.M., Kurra, N., Seredych, M., et al.: Bipolar carbide-carbon high voltage aqueous lithium-ion capacitors. Nano Energy 56, 151-159 (2019). https://doi.org/10.1016/j.nanoen.2018.11.042

57. Hou, J., Cao, C., Idrees, F., et al.: Hierarchical porous nitrogendoped carbon nanosheets derived from silk for ultrahigh-capacity battery anodes and supercapacitors. ACS Nano 9, 2556-2564 (2015). https://doi.org/10.1021/nn506394r

58. Lewandowski, A., Olejniczak, A., Galinski, M., et al.: Performance of carbon-carbon supercapacitors based on organic, aqueous and ionic liquid electrolytes. J. Power Sources 195, 58145819 (2010). https://doi.org/10.1016/j.jpowsour.2010.03.082

59. Zhang, F., Zhang, T.F., Yang, X., et al.: A high-performance supercapacitor-battery hybrid energy storage device based on graphene-enhanced electrode materials with ultrahigh energy density. Energy Environ. Sci. 6, 1623-1632 (2013). https://doi. org/10.1039/c3ee40509e

60. Ortaboy, S., Alper, J.P., Rossi, F., et al.: $\mathrm{MnO}_{x}$-decorated carbonized porous silicon nanowire electrodes for high performance supercapacitors. Energy Environ. Sci. 10, 1505-1516 (2017). https://doi.org/10.1039/c7ee00977a 


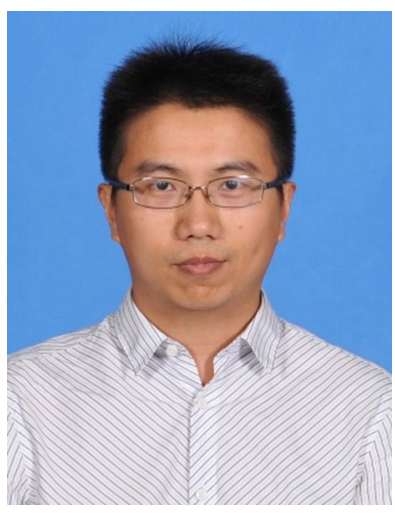

Linpo $\mathrm{Yu}$ is a Senior Research Fellow in Electrochemistry at the University of Nottingham Ningbo China. He is a member of the Royal Society of Chemistry. He received his BS in chemistry and $\mathrm{PhD}$ in physical chemistry (electrochemistry) from Wuhan University in 2003 and 2008 , respectively. He was a Research Assistant at Suzhou Institute of Nano-Tech and Nano-Bionics, CAS, from 2008 to 2013. Then, he carried out his postdoctoral research at the University of Nottingham in the UK for 2 years until he joined in the University of Nottingham Ningbo China in 2015. His main research interests include the supercapacitor and supercapattery electrode materials, ionic liquid electrolytes and thermochromic materials.

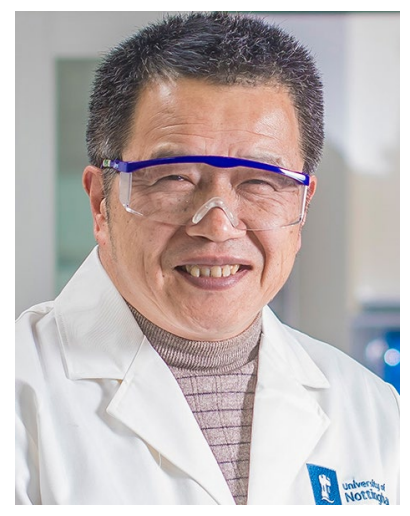

George Zheng Chen, CChem, FRSC, FRSA, FIMMM is a professor of electrochemical technologies in both the Nottingham and Ningbo campuses of the University of Nottingham. He received both his Teaching Diploma (1981, Jiujiang Teacher Training College) and MSc (1985, Fujian Normal University, Prof. Qixin Zhang) in China. After obtaining his $\mathrm{PhD}$ in 1992 from University of London (Imperial College, Prof. John Albery, FRS), he worked in the Universities of Oxford (1992-1994), Leeds (1994-1996) and Cambridge (1996-2003, Darwin). He also undertook academic duties in Jiangxi University (1985-1988) and Wuhan University (2000-2010, invited position). His research aims at electrochemical and liquid salt innovations for materials, energy and environment, producing $700+$ documented outputs, including the Fray-Farthing-Chen Cambridge Process. 